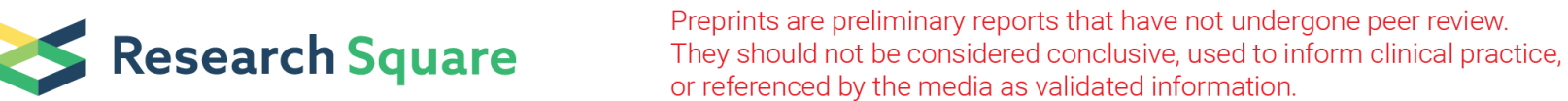

\section{Transcriptome co-expression network analysis identifies key genes and regulators of ripening kiwifruit ester biosynthesis}

\author{
Aidi Zhang ( $\square$ aidi2012@126.com ) \\ Ludong University https://orcid.org/0000-0001-5100-1554
}

\section{Qiuyun Zhang}

Zhejiang University

Jianzhao Li

Ludong University

Hansheng Gong

Ludong University

\section{Xinguang Fan}

Ludong University

\section{Yanqing Yang}

Ludong University

Xiaofen Liu

Zhejiang University

\section{Xueren Yin}

Zhejiang University

\section{Research article}

Keywords: aroma, kiwifruit, RNA-seq, ester biosynthesis, transcriptional regulation, ripening fruit, NAC, Dof

Posted Date: February 21st, 2020

DOI: https://doi.org/10.21203/rs.2.20183/v2

License: (c) (1) This work is licensed under a Creative Commons Attribution 4.0 International License.

Read Full License

Version of Record: A version of this preprint was published at BMC Plant Biology on March 6th, 2020. See the published version at https://doi.org/10.1186/s12870-020-2314-9. 


\section{Abstract}

Background: Aroma is an important organoleptic quality for fruit and has a large influence on consumer preference. Kiwifruit esters undergo rapid and substantial changes contributing to the flavor during fruit ripening. Part of enzymes and their coding genes have been indicated potential candidates for flavorrelated esters synthesis. However, there still exist obvious gaps in the biosynthetic pathways of esters and the mechanisms regulating ester biosynthesis in kiwifruit remain unknown.

Results: Using gas chromatography-mass spectrometry (GC-MS), volatile compounds of kiwifruit were quantified in response to ethylene (ETH, $\left.100 \mu \mathrm{l} / \mathrm{l}, 24 \mathrm{~h}, 20^{\circ} \mathrm{C}\right)$ and 1-methylcyclopropene (1-MCP, $1 \mu \mathrm{l} / \mathrm{l}, 24$ $\mathrm{h}, 20^{\circ} \mathrm{C}$ ). The results indicated that esters showed the most substantial changes enhanced by ethylene and were inhibited by 1-MCP. Correlations between RNA-seq results and concentrations of esters, constructed using Weighted Gene Co-Expression Network Analysis (WGCNA) indicated that three structural genes (fatty acid desaturase, AdFAD1 ; aldehyde dehydrogenase, AdALDH2 ; alcohol acyltransferase, AdAT17) had similar expression patterns that paralled the changes in total ester content, and AdFAD1 transcripts exhibited the highest correlation. In order to search for potential regulators for ester biosynthesis, 14 previously reported ethylene-responsive transcription factors (TFs) were included in the correlation analysis with esters and their biosynthetic genes. Using dual-luciferase assay, the in vivo regulatory activities of TFs on ester biosynthetic gene promoters were investigated and the results indicated that AdNAC5 and AdDof4 (DNA binding with one finger) trans-activated and trans-suppressed the AdFAD1 promoter.

Conclusions: The present study advanced the molecular basis of ripening-related ester biosynthesis in kiwifruit by identifying three biosynthetic related genes AdFAD1, AdALDH2 and AdAT17 by transcriptome analysis, and highlighted the function of two TFs by transactivation studies.

\section{Background}

Kiwifruit (Actinidia deliciosa) is one of the most recently developed and economically important fruit crops that is native to China and now has a global commercial distribution [1]. Kiwifruit are widely preferred by consumers due to their flavor and high value of nutrient compounds (eg. vitamin C) [2]. Aroma, together with sweetness and acidity generate the unique flavor of kiwifruit. The production of aroma volatile compounds is strongly ethylene-dependent [3]. In ethylene-suppressed kiwifruit, fruit softening was significantly delayed and aroma volatile production was dramatically reduced, which could be re-initiated by application of exogenous ethylene [4]. The aroma of kiwifruit is produced by a mixture of various volatile compounds, including alcohols, aldehydes, ketones, and esters [5], which makes kiwifruit a good model for understanding the biosynthesis and regulation of different volatile compounds.

Kiwifruit have long been used as material for volatile studies. The early reports on kiwifruit volatile compounds published by Young et al., identified ethyl butanoate, (E)-2-hexenal, (E)-2-hexenol, methyl and 
ethyl benzoate as the major components of kiwifruit aroma, by using simultaneous distillation extraction of volatiles [6]. Since then, kiwifruit volatiles have been extensively studied and expanded with 80 to 90 compounds identified so far $[7,8]$. In general, aldehydes are more abundant in unripe fruit with green notes and esters with fruity notes are abundant in ripe fruit and n-hexanal, (E)-2-hexenal and ethyl butanoate have been identified as specific kiwifruit volatiles [8]. Until now, many different methods have been developed and used for the analysis of the aroma compounds in kiwifruit, such as gas chromatography-mass spectrometry (GC-MS), which have further enlarged the categories of known volatile compounds in kiwifruit $[9,10]$.

Esters are major aromatic components responsible for the fruity aroma, which increases drastically with kiwifruit ripening $[8,9]$. The activity of lipoxygenase (LOX) enzyme contributes to this and increases markedly as fruit developed to the climacteric stage and some LOX genes are up-regulated by ethylene treatment, particularly $A d L o x 1$ and $A d L o x 5[11,12]$. Günther et al. indicated that ethylene regulated ester production in A. chinensis by inducing AAT gene expression and AAT-substrate precursor formation [13]. Based on the Actinidia EST database, 30 acyltransferases (ATs) were identified and phylogenetic analysis indicated 12 ATs are potential candidates for flavor-related esters synthesis [14]. However, several likely key enzymes and their coding genes involved in production of esters in kiwifruit have not been covered, such as fatty acid desaturase (FAD), hydroperoxide lyase (HPL), aldehyde dehydrogenase (ALDH). Some of the genes analyzed in kiwifruit, for instance $A d A D H 1$ and $A d A D H 2$ (alcohol dehydrogenase) are activated after waterlogging [15], which is not related to fruit ester production. Despite the importance of esters for kiwifruit flavor, there still exist obvious gaps in the biosynthetic pathways and regulatory mechanisms.

Moreover, the transcriptional regulation of the ester synthesis in kiwifruit, as well as most other fruit, has not been reported. At present, research on the transcriptional regulatory mechanism of fruit aroma production mainly concentrate on terpenes, including citrus CitAP2.10 for (+)-valencene and CitERF71 for E-geraniol, and kiwifruit $A a N A C 2 / 3 / 4$ for monoterpene biosynthesis $[16,17,18]$. In persimmon fruit, the ERFS could regulate the $A D H$ promoter and might be key components in persimmon fruit astringency removal [19]. In kiwifruit, ACNAC5 increased significantly in response to propylene and showed correlation with aroma volatile production patterns, suggesting its potential role in the regulation of $A C A A T$ and aroma volatile biosynthesis during ripening [3]; However, such findings only hint at the potential of TFs in ester related pathway regulation, and role of these ERFs and other TFs on esters biosynthesis remains unclear. In our previous research, three major ripening traits in kiwifruit, including texture, ethylene production and starch degradation were analyzed and a range of ethylene responsive TFs were identified [20]. Only AdDof3, AdDof4 (DNA binding with one finger) and AdNAC5 were identified as targeting genes related to kiwifruit ripening and softening [20], however, and it was assumed that the remaining TFs may also be involved in other regulating other ripening related traits such as aroma.

Based on the academic background of ester biosynthesis in kiwifruit, the objectives of this research were to identify the key genes for ester production and the underlying transcriptional regulatory mechanisms contributing to the control of their expression. The volatile compounds were quantified by GC-MS, using 
ethylene treated, 1-MCP treated and control fruit. Three key structural genes were predicted by transcriptomic results, by using Weighted Gene Co-Expression Network Analysis (WGCNA). Furthermore, AdNAC5 and AdD of 4 were provisionally identified as transcriptional regulator active on the AdFAD1 promoter. Thus, these results not only filled in some of the gaps in the ester biosynthetic pathway in kiwifruit, but also identified TFs involved in the regulatory mechanisms of aroma production.

\section{Results}

\section{Volatile compounds analysis in ripening kiwifruit}

Alcohols, terpenes, aldehydes, ketones and esters were analyzed in the postharvest kiwifruit treated with ethylene, 1-MCP or control, respectively. Among total alcohols, terpenes, aldehydes, ketones and esters, esters were the most numerous compounds present at the ripening stage, with the values increasing from $236.23 \mu \mathrm{g} / \mathrm{kg}$ at $0 \mathrm{~d}$ and reaching peaks of $47373.07 \mu \mathrm{g} / \mathrm{kg}$ in ETH (10 d), 23232.26 in control (18 d) and $499.82 \mu \mathrm{g} / \mathrm{kg}$ in 1-MCP treated samples (18 d), respectively (Fig. 1A). Concentrations of main volatile compounds can be found in Additional file 1. (E)-2-Hexenal stayed high level in most unripen fruit and identified as the major contributors to kiwifruit aroma with green notes [21]. Besides, methyl butanoate, methyl benzoate, ethyl butanoate and ethyl benzoate were the most abundant compounds in ripen fruit (Additional file 2: Fig. S1). During storage, these four esters showed similar changes: induced by ethylene and repressed by 1-MCP. The production of esters increased sharply in control (17 d, $18 d$ ) and ETH fruit $(8 \mathrm{~d}, 10 \mathrm{~d})$, concomitantly with endogenous climacteric ethylene production, while they all remained at the basal level throughout storage in 1-MCP treated fruit (Fig. 1B). Other volatiles contributed much less to the aroma profile, compared with these four esters (Fig. 1C). PCA analysis showed that esters compounds located the nearest with ethylene, suggesting the strongly correlations between them and the possibility of esters associated with kiwifruit ripening (Additional file 2: Fig. S2).

\section{WGCNA of RNA-seq data}

The WGCNA was performed to investigate the co-expression networks, in which all co-expressed genes were connected to each other with varying correlation strengths. Genes were partitioned into twenty-two co-expression modules (Fig. 2A). The content of esters was positively correlated with gene expression in the 'blue' module and negatively correlated in the 'magenta' module, with a coefficient of $0.82\left(P=4 \times 10^{-}\right.$ $\left.{ }^{5}\right)$ and $-0.78\left(P=1 \times 10^{-4}\right)$, respectively (Fig. 2B). The coefficients for modules with the other four types of volatile compounds were all lower than 0.7 (Fig. 2B). Based on correlation ( $r>0.7)$ between genes in the two modules and ester content, a total of 1,896 genes were identified.

Using the 1,896 genes, GO annotation was carried out. GO annotation analysis revealed that genes could be summarized in three main functional categories, including cellular component, molecular function and biological process. Five groups, including cell, cell part, cellular process, metabolic process and organelle, were the main classifications for more than $60 \%$ of the genes (Fig. 3 ). 
Based on WGCNA narrowed the scope of differentially expressed genes (DEGs) from RNA-seq and focused on biosynthetic pathways for esters, two aldehyde dehydrogenases (AdALDH1, AdALDH2), two fatty acid desaturases (AdFAD1, AdFAD2), one alcohol dehydrogenase (AdADH3) and one alcohol acyltransferase (AdAT17) [22] were identified. Using TBTools software, gene transcripts abundance is indicated with a heatmap (Fig. 4A). Among the genes, AdAT17, AdALDH2 and AdFAD1 exhibited similar pattern, which were obviously induced by exogenous ethylene and suppressed by 1-MCP treatment, while $A d A D H 3, A d A L D H 1$ and $A d F A D 2$ were less responsive to two treatments (Fig. 4A). Increases in abundance of transcripts of $A d A T 17, A d A L D H 2$ and $A d F A D 1$ were confirmed by real-time PCR in postharvest 'Hayward' kiwifruit. The results indicated that AdAT17, AdALDH2 and AdFAD1 were all responsive to exogenous ethylene at $1 \mathrm{~d}$ and were also accumulated in parallel with endogenous ethylene in both ETH and control fruit (Fig. 4B). 1-MCP treatment kept expression of AdAT17 and AdALDH2 at basal level, while it only delayed the increase in expression of $A d F A D 1$ (Fig. 4B). The most significant difference was observed for AdAT17, its relative expression reaching the maximum (186.53) at $8 \mathrm{~d}$ in ETH, compared to 0.93 for CK and 0.05 for 1 -MCP at $8 \mathrm{~d}$ (Fig. 4).

\section{Regulatory effects of transcription factors on two main ester biosynthesis genes (AdFAD1 and AdAT17)}

Correlation analysis with ester content, and three candidate genes (AdFAD1, AdAT17 and AdALDH2) potentially being involved in ester biosynthesis with 14 previously characterized ripening related TFs [20], were conducted and visualized by Cytoscape (v3.7.1, USA). As shown in Figure 5, all three ester biosynthesis genes exhibit positive correlations with ester content, with AdFAD1 showing the highest positive correlation. For the 14 TFs, the transcript changes in AdBEE1, AdERF10, AdNAC6, AdGT1, AdDof3 and AdNAC5 positively correlated with ester content, while AdDof4, AdHB1 and AdbZIP1 showed negative correlations (Fig. 5). Between ester biosynthesis genes and TFs, the highest positive correlation was observed between AdBEE1 and AdAT17, followed by AdBEE1 and AdFAD1, while the highest negative correlation was found between AdDof4 and AdFAD1 (Fig. 5).

To extend beyond the digital analysis of the relationship between TFs, structural genes, and ester content, the in vivo regulatory roles of TFs on the promoters of two of the main candidate targets (AdAT17 and $A d F A D 1)$ were tested, using dual-luciferase assay. Unfortunately, the failure of amplification of the $A d A L D H 2$ promoter precluded its inclusion in this analysis. The results indicated that AdNAC5 could significantly trans-activate the AdFAD1 promoter, with over 2-fold induction (Fig. 6A), whereas for the AdFAD1 promoter, AdD of 4 acted as a repressor, reducing the transcriptional activity to 0.67 , compared to the basal activity set as 1 (Fig. 6A). None of the examined TFs showed significant regulatory effects (neither activation nor repression) on the AdAT17 promoter, (Fig. 6B).

\section{Discussion}

\section{Regulatory roles of ethylene and 1-MCP on esters accumulation}

Understanding aroma formation is critical for kiwifruit quality and marketability, especially the production of esters, which are the main components for aroma in ripening kiwifruit (Fig. 1A). During kiwifruit 
ripening, the flavor changes from 'grassy' and 'green' to 'fruity', and this is manifested by increases in esters and decreases in aldehydes [21]. It was suggested that the accumulation of esters during ripening were likely driven by ethylene $[8,12]$. The production of esters, especially ethyl butanoate and methyl butanoate, appeared to be strongly dependent on ethylene signal [3]. Additionally, in ethylene-suppressed transgenic lines kiwifruit, esters were dramatically reduced, while the major volatiles produced in ethyleneunsuppressed fruit were ethyl butanoate, methyl butanoate, and ethyl acetate [4]. The present study also found that ethylene treatment accelerated esters accumulation compared with control fruit, and 1-MCP treatment showed the opposite effects on ester production. Four ester compounds (methyl butanoate, methyl benzoate, ethyl butanoate and ethyl benzoate) were found as the main contributors to the total ester for ripening 'Hayward' kiwifruit (Fig. 1C), which were similar to previous findings [8, 9]. During 'Hayward' storage at $0{ }^{\circ} \mathrm{C}$, the total esters, which consisted mainly of methyl and ethyl butanoate, increased after 9 weeks storage but dropped after 21 weeks storage, and methyl and ethyl benzoate showed similar trends [8]. Butanoates were the main fruity esters in both 'Hayward' and 'Hort16A' fruit, which significantly increased during ripening and in over-ripe fruit. Butanoates contributed to less than

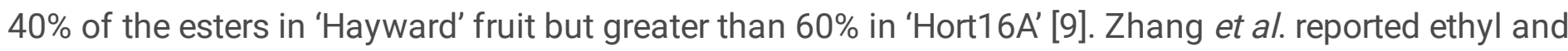
methyl butanoate levels increased late in the ripening process of 'Bruno' [12]. In 'Hort16A' kiwifruit, ethylene treatment $(100 \mathrm{ppm}, 24 \mathrm{~h})$ can restore the significant reduction of aroma-related esters by cold storage $\left(1.5^{\circ} \mathrm{C}\right)$ for two or four months [23]. Moreover, the effects of ethylene and/or 1-MCP on esters has also been widely reported in other fruit. In pear fruit, concentrations of both total volatiles and esters were lower in 1-MCP treated fruit compared with control [24]. In apple fruit, regulation of ethylene has a major effect on volatiles production, AAT enzyme is an important point in the modulation of ester production under ethylene regulation [25]. Furthermore, ethylene is also known to be important for the expression of some volatile-related genes in melon and tomato $[26,27]$.

The impact of ethylene on ester production in climacteric fruit is well accepted. Thus, at the physiology level, we recorded the changes in aroma compounds during the whole storage and maturation period. The present findings confirmed a burgeoning increase in esters content of 'Hayward' coinciding with fruit softening, which was accelerated by ethylene treatment and delayed by the ethylene action inhibitor 1MCP. These results directly conform the important impact of ethylene for ester biosynthesis regulation.

\section{Candidate target genes for ester biosynthesis}

Beyond the physiology studies, the molecular aspects underlying ester biosynthesis were also widely studied. Yahyaoui et al. showed that AAT was involved in the generation of aroma volatile esters during melon ripening [26]. Transgenic apple plants with reduced MpAAT1 expression showed reduced levels of most key esters [22]. MdAAT2 was also positively correlated with AAT enzyme activity and ester production in 'Golden Delicious' [28]. Qian et al. demonstrated the $A A T$ gene mainly determined the contents of berry volatile esters [29]. Balbontin et al. indicated that papaya fruit VpAAT1 encoded a functional enzyme with high AAT activity, contributing to the formation of benzyl acetate, and its expression was dependent on ethylene [30]. Cumplido-Laso et al. observed a significant reduction in ester production in the strawberry fruit receptacle when FaAAT2 expression was transiently downregulated [31]. 
Besides AAT, there are multiple other enzymes and their coding genes involved in ester production, such as fatty acid desaturase (FAD), alcohol dehydrogenase (ADH), lipoxygenase (LOX). In peach fruit, HA (hot air) and UV-C treatments effectively promoted the emission of esters, which were consistent with upregulations on PpAAT, PpFAD and PpACX1/2 expression [32]. In pear fruit, PuLOXs and PUAAT were inhibited dramatically by 1-MCP, and the suppression of PuLOXs and PUAAT genes may be ascribed to the reason for lower content of total volatiles and esters [24]. Moreover, overexpression of FAD (FAD3 and $F A D 7$ ) in tomato fruit promoted linolenic acid content and enhanced an accumulation of volatiles [33]. In tomato, LOXC has been shown to be involved directly in the production of aroma volatiles [27]. In kiwifruit, the enzymes and their coding genes for ester were mainly focused on lipoxygenase (LOX) and alcohol acyltransferase (AAT). The activity of LOX enzyme tended to increase with fruit ripening and were up-regulated by ethylene treatment [11, 12], although in tomato ethylene stimulates accumulation of transcripts from some $L O X$ genes, including TomLOXC involved in flavor volatile production, and suppresses other $L O X$ genes [27]. The activity of AAT enzyme is exclusive to ethylene-producing kiwifruit and the production of esters depends on ethylene-regulated AAT enzyme levels [13]. As for the coding genes, six LOX genes (AdLox1-6) and 12 AATs (AdAT1/2/ 6/ 17/22, AeAT9, ACAT15/ 16/20/ 23/24, AaAT18) were identified, and AdLox1, AdLox5 and 12 AATs were thought to be potential candidates for flavor-related esters synthesis $[11,12,14]$. Günther et al. confirmed that accumulation of $A A T 1, A A T 2$, $A A T 15, A A T 16, A A T 17$ and $A A T 18$ transcripts is dependent on ethylene-induced ripening [13]. ACAAT expression exhibited a dramatic increase in propylene treated kiwifruit [3]. The present transcriptomebased analysis and WGCNA analysis indicated three key genes (AdALDH2, AdFAD1 and AdAT17) are critically important for kiwifruit ester production, and highlights the importance of these genes for understanding ester metabolism in kiwifruit. Phylogenetic analysis indicated that AdAT17 clustered with flavor-related AATs from other plant species, including FaAAT2, VpAAT1, CmAAT1-3 and apple AAT1-4 (Additional file 2: Fig. S3), while AdFAD1 clustered closest with AtFAD2 (Additional file 2: Fig. S4), which acts on fatty acids in conjunction with the activity of the ER 18:1 desaturase [34].

\section{The proposed transcriptional mechanism for fruit ester biosynthesis}

Beyond the biosynthesis pathway, there is very little information about the TFs involved in transcriptional control of ester metabolism and recent investigations have mainly been conducted on terpene biosynthesis. For instance, kiwifruit AaNAC2/3/4 are involved in the transcriptional regulation of TPS genes (AaTPS1) and monoterpene production [18]; citrus CitAP2.10 and CitERF71 regulate corresponding TPS genes (CSTPS1 and CitTPS16) and contributed to (+)-valencene and E-geraniol metabolism, respectively $[16,17]$. Moreover, in strawberry, an ERF-MYB transcription complex was found to regulate furaneol biosynthesis and the FaQR promoter [35]. However, few TFs have been reported that have regulatory effects on biosynthesis of esters. The present finding indicated that one of the key biosynthetic genes (AdFAD1) could be activated by AdNAC5 and suppressed by AdDof4 (Fig. 6), which provided an elementary example of a transcriptional regulatory module for esters metabolism. NAC transcription factors $(A a N A C 2 / 3 / 4)$ are involved in kiwifruit terpene biosynthesis [18], however, the phylogenetic tree aligned the AdNAC5 sequence with the reported NACs in A. chinensis and A. arguta and AdNAC5 does not have high homology to the kiwifruit NACs involved in terpene biosynthesis and the more closely related 
genes (AT5G61430.1, AT5G07680.1 and AT3G18400.1) in Arabidopsis thaliana are all functionally uncharacterized (Additional file 2: Fig. S5).

In plants, Dof transcription factors have been widely reported to be involved in many biological processes, such as sweet potato $S R F 1$, maize Zmdof3 and kiwifruit AdDof3 that participate in regulating carbohydrate and starch metabolism [20,36,37]. Banana MaDof23 can interact with MaERF9 in regulating fruit ripening [38], however, the roles of Dof transcription factors in aroma production have rarely been investigated. Thus, the regulatory roles of NAC and Dof on kiwifruit ester-related genes not only provide new information about fruit aroma (especially for ester biosynthesis) regulation, but also have suggested the novel transcription factors that may contribute volatile metabolism.

\section{Conclusions}

In summary, using GC-MS the present study indicated the role of the four main esters (methyl butanoate, methyl benzoate, ethyl butanoate and ethyl benzoate) in ripening 'Hayward' kiwifruit. Further investigation based on RNA-seq and WGCNA, suggested the three key structural genes (AdFAD1, AdAT17 and $A d A L D H 2$ ) for ester production. Furthermore, testing the role of TFs in transcriptional regulation characterized AdNAC5 as a transcriptional activator and AdDof4 as a transcriptional repressor of the AdFAD1 promoter. Overall, these findings provide new insights into the production of volatiles in ripening kiwifruit and the roles of specific structural genes and TFs in ester metabolism.

\section{Methods}

\section{Plant material and treatments}

The mature kiwifruit (Actinidia deliciosa [A. Chev.] C.F. Liang et A.R. Ferguson var. deliciosa cv. Hayward) were harvested in the 2015 season from a commercial orchard (Shanxi, China), with a mean total soluble solid (TSS) of $6.19 \%$. Kiwifruit 'Hayward' is a breeding plant material originally from New Zealand and available at Wuhan Botanical Garden, Chinese Academy of Sciences. We declare that the kiwifruit materials in this study comply with institutional, national, and international guidelines for the collection and cultivation of any plant materials. Fruit of uniform size without visible defects were divided into three batches. One batch was treated with $\mathrm{C}_{2} \mathrm{H}_{4}\left(\mathrm{ETH}, 100 \mathrm{\mu l} \mathrm{I}^{-1}, 24 \mathrm{~h}, 20^{\circ} \mathrm{C}\right)$, one was treated with 1-MCP $\left(1 \mu \mathrm{I}^{-}\right.$ $1,24 \mathrm{~h}, 20^{\circ} \mathrm{C}$ ) and the third batch was sealed in air as control (air, $24 \mathrm{~h}, 20^{\circ} \mathrm{C}$ ) and they were all placed at $20^{\circ} \mathrm{C}$. Each treatment contained three biological replicates of approximately 200 fruit. At each sampling point, three replicates of four fruit were collected from each batch. Samples were taken at intervals and the materials (small pieces of outer pericarp free of skin or seeds) were frozen with liquid nitrogen and stored at $-80^{\circ} \mathrm{C}$. The treatment and sample collection, as well as the ripening related indexes (firmness, cell wall materials, starch, TSS, ethylene) were conducted as described by Zhang et al [20].

\section{Volatile analysis by GC-MS}


Measurement of postharvest kiwifruit volatiles and analysis were carried out according to Zhang et al. and Wu et al $[12,39]$. Frozen flesh tissue was ground in liquid nitrogen and a total of $2 \mathrm{~g}$ flesh transferred to a $10 \mathrm{~mL}$ vial containing $3 \mathrm{~mL}$ saturated sodium chloride solution. Each sample point had three replicates. Before the vials were sealed, $10 \mu \mathrm{L}$ of 2 -octanol $(0.8 \mathrm{mg} / \mathrm{mL})$ was added as the internal standard. After vigorous vortexing, samples were equilibrated at $45^{\circ} \mathrm{C}$ for $30 \mathrm{~min}$ and volatiles collected with a solid-phase microextraction (SPME) fiber coated with a $65 \mu \mathrm{m}$ of polydimethylsiloxane and divinylbenzene (PDMS-DVB) (Supelco Inc., Bellefonte, PA, USA). The volatile compounds were identified using an Agilent $7890 \mathrm{~N}$ gas chromatograph coupled with an Agilent $5975 \mathrm{C}$ mass spectrophotometer (Agilent, Palo Alto, CA, USA). The Agilent 5975C mass spectrophotometer was equipped with a DB-WAX column ( $30 \mathrm{~m}, 0.32 \mathrm{~mm}, 0.25 \mu \mathrm{m}$, J\&W Scientific, Folsom, CA, USA). The oven temperature program started at $40^{\circ} \mathrm{C}$ and increased to $100^{\circ} \mathrm{C}$ at a rate of $3{ }^{\circ} \mathrm{C} \mathrm{min}-1$, followed by a ramp to $245^{\circ} \mathrm{C}$ at a rate of $5^{\circ} \mathrm{C} \mathrm{min}{ }^{-1}$. Helium was used as carrier gas at the flow rate of $1.0 \mathrm{ml} \mathrm{min}^{-1}$. The source temperature for the MS was $230^{\circ} \mathrm{C}$, and the column effluent was ionized by electron energy of $70 \mathrm{eV}$ with the transfer interface zone at $250^{\circ} \mathrm{C}$. The mass scanning was done over the range of $35-350 \mathrm{~m} / \mathrm{z}$. Identification of volatile compounds was further validated by comparing their electron ionization mass spectra with the NIST/EPA/NIH Mass Spectral Library (NIST-08) and the retention time of authentic standards.

\section{RNA extraction and cDNA synthesis}

Total RNA was isolated from frozen kiwifruit flesh following the protocol described by Yin et al [40]. From each sample, $1 \mu \mathrm{g}$ of total RNA in a $20 \mu \mathrm{L}$ solution was reverse transcribed using the PrimeScript $1^{\text {st }}$ Strand cDNA synthesis kit (TaKaRa, Dalian, China) following the manufacturer's protocol. At each sampling point, RNA extraction and cDNA synthesis were performed with three biological replicates.

\section{RNA-seq, WGCNA and gene network visualization}

The details of RNA-seq were described by Zhang et al [20]. The SRA accession number are SRR6885590SRR6885601, SRR7630964-SRR7630969.

Co-expression networks were created using WGCNA (v1.29) package in R [41]. The data used for WGCNA co-expression network analysis were the five classes of aroma components (terpenes, alcohols, aldehydes, ketones and esters) produced during storage and all RNA-seq genes after discarding none detectable genes $(F P K M=0)$. A total of 26,111 genes were used as input to the signed WGCNA network construction. The automatic network construction function block wise was used to build modules. In standard WGCNA networks, soft power was set to 6, min Module Size was 30, and the merge Cut Height value was 0.25 . The initial clusters were merged on eigengenes. Eigengene value was calculated for each module, which was used to search the association with flavor compounds. WGCNA is accomplished using a soft threshold to preserve the continuous nature of the data set and eliminate the need to set an arbitrary correlation score cutoff. Candidate hub genes in "blue" and "magenta" were picked by threshold at a value of 0.7 . The network of ester content, transcription factors and candidate target genes were visualized by Cytoscape (v3.7.1, USA). 


\section{Real-time PCR analysis}

Real-time PCR was carried out with a LightCycler ${ }^{\circledR} 480$ SYBR Green I Master (Roche) kit using a LightCycler ${ }^{\circledR} 480$ instrument (Roche). The information about structural genes is listed in Additional file 3: Table S1. The primers for real-time PCR analysis were designed by primer3 (http://frodo.wi.mit.edu/primer3) and are listed in Additional file 3: Table S2. The specificity of primers was double checked by melting curve and PCR product resequencing described by Yin et al [40]. Abundance of cDNA templates was monitored with kiwifruit actin, which is stably expressed across kiwifruit ripening stages [11]. Three biological replicates were analyzed for real-time PCR. The PCR program was initiated with a preliminary step of $5 \mathrm{~min}$ at $95^{\circ} \mathrm{C}$, followed by 45 cycles at $95^{\circ} \mathrm{C}$ for $10 \mathrm{~s}$, $60{ }^{\circ} \mathrm{C}$ for $10 \mathrm{~s}$, and $72{ }^{\circ} \mathrm{C}$ for $15 \mathrm{~s}$. Data were analyzed with the $2^{-\Delta \mathrm{Ct}}$ method to calculate the relative expression levels of genes, by transcript abundance.

\section{Gene isolation and promoter cloning}

Based on the RNA-Seq results, differentially expressed genes (DEGs) associated with ester biosynthesis were isolated and verified by PCR with gene-specific primers (Additional file 3: Table S2) using cDNA from cv. 'Hayward'. The transcription factors were derived from our previous report [20].

Using the RNA-Seq results and kiwifruit genome database for reference [42], the promoter sequences were amplified (Additional file 3: Table S3). Genomic DNA (gDNA) from 'Hayward' served as template for amplifying AdAT17 and AdFAD1 promoters. The primers are listed in Additional file 3: Table S4.

\section{Dual-Luciferase assays}

Full length sequences of eleven transcription factors were integrated into pGreen $\otimes 002962$-SK vector (SK) [20], while promoters of $A d A T 17$ and AdFAD1 were inserted into the pGreen $\otimes 0800$-LUC vector (LUC).

The recombinant SK and LUC vectors were transfected into Agrobacterium tumefaciens GV3101 and stored at $-80^{\circ} \mathrm{C}$ with glycerol. Before injection, the glycerol stocks were activated on new LB plates to which was added $50 \mathrm{\mu g} \mathrm{ml}^{-1}$ kanamycin and $25 \mathrm{\mu g} \mathrm{ml}^{-1}$ gentamycin. Then the Agrobacterium with recombinant vectors were suspended in infiltration buffer $\left(10 \mathrm{mM} \mathrm{MgCl}_{2}, 10 \mathrm{mM} \mathrm{MES}, 150 \mathrm{mM}\right.$ acetosyringone, $\mathrm{pH}$ 5.6) to the optimal density $\left(\mathrm{OD}_{600} \sim 0.75\right)$. After that, $100 \mu \mathrm{l}$ of Agrobacterium containing promoters were mixed with $1 \mathrm{ml}$ of Agrobacterium cultures containing transcription factors, then were injected into tobacco (Nicotiana tabacum) leaves using needleless syringes. The empty SK vector was injected as control. Three days after infiltration, the dual luciferase assay reagents (Promega) were used to measure LUC and REN fluorescence intensities following the manufacturer's instructions. The dual-luciferase assays were performed with three biological replicates.

\section{Statistical analysis}


Results were analyzed by DPS7.05 (Zhejiang University, Hangzhou, China) to compare significant differences, using least significant difference (LSD) at the $5 \%$ level. The heatmap was drawn with TBtools software. Figures were drawn with Origin 8.0 (Microcal Software Inc., Northampton, MA, USA). The statistical significance was calculated with a Student's $t$-test $\left({ }^{\star} P<0.05,{ }^{\star \star} P<0.01\right.$ and $\left.{ }^{\star \star \star} P<0.001\right)$.

\section{Abbreviations}

GC-MS: gas chromatography-mass spectrometry; ETH: ethylene; 1-MCP: 1-methylcyclopropene; WGCNA: Weighted Gene Co-Expression Network Analysis; LOX: lipoxygenas; AT: acyltransferases; AAT: alcohol acyltransferase; ADH: alcohol dehydrogenase; FAD: fatty acid desaturase; HPL: hydroperoxide lyase; ALDH: aldehyde dehydrogenase; d: day; TFs: transcription factors; Dof: DNA binding with one finger

\section{Declarations}

\section{Acknowledgment}

We thank Prof. Don Grierson (University of Nottingham, UK) for extensive revisions to the manuscript, and Miss Rong Jing (Agricultural Experiment Station, Zhejiang University) for plant cultivation.

\section{Authors' contributions}

YXR and ZAD designed the study. ZAD, LJZ, ZQY and LXF performed the experiments. ZQY, FXG, GHS and $Y Y Q$ analyzed the data; $Y X R$ and ZAD wrote the manuscript. All authors read and approved the final manuscript.

\section{Funding}

This research was supported by the National Key Research and Development Program (2018YFD1000200), the National Natural Science Foundation of China (31722042, 31901737), and the Fok Ying Tung Education Foundation, China (161028). The funders had no role in the material creation, designing the study, analysis data and in writing the manuscript.

\section{Availability of data and materials}

The raw data have been submitted [20]. The SRA accession number are SRR6885590-SRR6885601, SRR7630964-SRR7630969.

\section{Ethics approval and consent to participate}

Not applicable.

\section{Consent for publication}

Not applicable. 


\section{Competing interests}

The authors declare that they have no competing interests.

\section{Author details}

${ }^{1}$ School of Food Engineering, Ludong University, Yantai, Shandong, 264025, PR China

2 BioNanotechnology Institute, Ludong University, Yantai, Shandong, 264025, PR China

${ }^{3}$ College of Agriculture \& Biotechnology, Zhejiang University, Zijingang Campus, Hangzhou, 310058, PR China

${ }^{4}$ School of Agriculture, Ludong University, Yantai, Shandong, 264025, PR China

\section{References}

1. Huang H, Ferguson AR. Kiwifruit in China. New Zeal J Crop Hort. 2001; 29: 1-14.

2. Rassam M, Laing W. Variation in ascorbic acid and oxalate levels in the fruit of Actinidia chinensis tissues and genotypes. J Agric Food Chem. 2005; 53: 2322-6.

3. Mitalo OW, Tokiwa S, Kondo Y, Otsuki T, Galis L, Suezawa K, Kataoka L, Doan AT, Nakano R, Ushijima K, Kubo Y. Low Temperature Storage Stimulates Fruit Softening and Sugar Accumulation Without Ethylene and Aroma Volatile Production in Kiwifruit. Front Plant Sci. 2019; 10: 888.

4. Atkinson RG, Gunaseelan K, Wang MY, Luo L, Wang TC, Norling CL, Johnston SL, Maddumage R, Schröder R, Schaffer RJ. Dissecting the role of climacteric ethylene in kiwifruit (Actinidia chinensis) ripening using a 1-aminocyclopropane-1-carboxylic acid oxidase knockdown line. J Exp Bot. 2011; 62: 3821-35.

5. Marsh KB, Friel EN, Gunson A, Lund C, MacRae E. Perception of flavor in standardised fruit pulps with additions of acids or sugars. Food Qual Prefer. 2006; 17: 376-86.

6. Young H, Paterson VJ, Burns DJW. Volatile aroma constituents of kiwifruit. J Sci Food Agric. 1983; 34: 81-5.

7. Friel EN, Wang M, Taylor AJ, MacRae EA. In vitro and in vivo release of aroma compounds from yellow-fleshed kiwifruit. J Agric Food Chem. 2007; 55: 6664-73.

8. Young $\mathrm{H}$, Paterson VJ. The effects of harvest maturity, ripeness and storage on kiwifruit aroma. J Sci Food Agric. 1985; 36: 352-8.

9. Wang MY, MacRae E, Wohlers M, Marsh K. Changes in volatile production and sensory quality of kiwifruit during fruit maturation in Actinidia deliciosa 'Hayward' and A. chinensis 'Hort16A'. Postharvest Biol Tec. 2011; 59: 16-24.

10. Zhang $\mathrm{CY}$, Zhang Q, Zhong $\mathrm{CH}$, Guo MQ. Analysis of volatile compounds responsible for kiwifruit aroma by desiccated headspace gas chromatography-mass spectrometry. J Chromatogr A. 2016; 
1440: 255-9.

11. Zhang B, Chen KS, Bowen J, Allan A, Espley R, Karunairetnam S, Ferguson I. Differential expression within the LOX gene family in ripening kiwifruit. J Exp Bot. 2006; 57: 3825-36.

12. Zhang B, Yin XR, Li X, Yang SL, Ferguson IB, Chen KS. Lipoxygenase gene expression in ripening kiwifruit in relation to ethylene and aroma production. J Agric Food Chem. 2009; 57: 2875-81.

13. Günther CS, Heinemann K, Laing WA, Nicolau L, Marsh KB. Ethylene-regulated (methylsulfanyl) alkanoate ester biosynthesis is likely to be modulated by precursor availability in Actinidia chinensis genotypes. J Plant Physiol. 2011; 168: 629-38.

14. Crowhurst RN, Gleave AP, MacRae EA, Ampomah-Dwamena C, Atkinson RG, Beuning LL, Bulley SM, Chagne D, Marsh KB, Matich AJ, Montefiori M, Newcomb RD, Schaffer RJ, Usadel B, Allan AC, Boldingh HL, Bowen JH, Davy MW, Eckloff R, Ferguson AR, Fraser LG, Gera E, Hellens RP, Janssen BJ, Klages K, Lo KR, MacDiarmid RM, Nain B, McNeilage MA, Rassam M, Richardson AC, Rikkerink EHA, Ross GS, Schröder R, Snowden KC, Souleyre EJF, Templeton MD, Walton EF, Wang D, Wang MY, Wang YY, Wood M, Wu R, Yauk YK, Laing WA. Analysis of expressed sequence tags from Actinidia: applications of a cross species EST database for gene discovery in the areas of flavor, health, color and ripening. BMC Genomics. 2008; 9: 351.

15. Zhang JY, Huang SN, Chen YH, Wang G, Huo ZR. Identification and characterization of two waterlogging responsive alcohol dehydrogenase genes (AdADH1 and AdADH2) in Actinidia deliciosa. Mol Breeding. 2017; 37: 52.

16. Shen SL, Yin XR, Zhang B, Xie XL, Jiang Q, Grierson D, Chen KS. CitAP2.10 activation of the terpene synthase CSTPS1 is associated with the synthesis of (+)-valencene in 'Newhall' orange. J Exp Bot. 2016; 67: 4105-15.

17. Li X, Xu YY, Shen SL, Yin XR, Klee H, Zhang B, Chen KS. Transcription factor CitERF71 activates the terpene synthase gene CitTPS16 involved in the synthesis of E-geraniol in sweet orange fruit. J Exp Bot. 2017; 68: 4929-38.

18. Nieuwenhuizen NJ, Chen XY, Wang MY, Matich AJ, Perez RL, Allan AC, Green SA, Atkinson RG. Natural variation in monoterpene synthesis in kiwifruit: Transcriptional regulation of terpene synthases by NAC and ETHYLENE-INSENSITIVE3-Like transcription factors. Plant Physiol. 2015; 167 : 1243-58.

19. Zhu QG, Gong ZY, Huang JW, Grierson D, Chen KS, Yin XR. High-CO 2 /hypoxia-responsive transcription factors DkERF24 and DkWRKY1 interact and activate DkPDC2 promoter. Plant Physiol. 2019; 180: 621-33.

20. Zhang AD, Wang WQ, Tong Y, Li MJ, Grierson D, Ferguson IB, Chen KS, Yin XR. Transcriptome analysis identifies a zinc finger protein regulating starch degradation in kiwifruit. Plant Physiol. 2018; 178: 850-63.

21. Garcia CV, Quek SY, Stevenson RJ, Winz RA. Kiwifruit flavour: A review. Trends Food Sci Tech. 2012; 24: 82-91. 
22. Souleyre EJF, Chagné D, Chen XY, Tomes S, Turner RM, Wang MY, Maddumage R, Hunt MB, Winz RA, Wiedow C, Hamiaux C, Gardiner SE, Rowan DD, Atkinson RG. The AAT1 locus is critical for the biosynthesis of esters contributing to 'ripe apple' flavour in 'Royal Gala' and 'Granny Smith' apples. Plant J. 2014; 78: 903-15.

23. Günther CS, Marsh KB, Winz RA, Harker RF, Wohlers MW, White A, Goddard MR. The impact of cold storage and ethylene on volatile ester production and aroma perception in 'Hort16A' kiwifruit. Food Chem. 2015; 169: 5-12.

24. Li GP, Jia HJ, Li JH, Li HX, Teng YW. Effects of 1-MCP on volatile production and transcription of ester biosynthesis related genes under cold storage in 'Ruanerli' pear fruit (Pyrus ussuriensis Maxim). Postharvest Biol Tec. 2016; 111: 168-74.

25. Defilippi BG, Dandekar AM, Kader AA. Relationship of ethylene biosynthesis to volatile production, related enzymes, and precursor availability in apple peel and flesh tissues. J Agric Food Chem. 2005; 53: 3133-41.

26. Yahyaoui FEL, Wongs-Aree C, Latché A, Hackett R, Grierson D, Pech JC. Molecular and biochemical characteristics of a gene encoding an alcohol acyl-transferase involved in the generation of aroma volatile esters during melon ripening. Eur J Biochem. 2002; 269: 2359-66.

27. Chen GP, Hackett R, Walker D, Taylor A, Lin ZF, Grierson D. Identification of a specific isoform of tomato lipoxygenase (TomloxC) involved in the generation of fatty acid-derived flavor compounds. Plant Physiol. 2004; 136: 2641-51.

28. Li DP, Xu YF, Xu GM, Gu LK, Li DQ, Shu HR. Molecular cloning and expression of a gene encoding alcohol acyltransferase (MdAAT2) from apple (cv. Golden Delicious). Phytochemistry. 2006; 67: 65867.

29. Qian X, Liu YR, Zhang GJ, Yan AL, Wang HL, Wang XY, Pan QH, Xu HY, Sun L, Zhu BQ. Alcohol acyltransferase gene and ester precursors differentiate composition of volatile esters in three interspecific hybrids of Vitis labrusca $\times V$. Vinifera during berry development period. Food Chem. 2019; 295: 234-46.

30. Balbontin C, Gaete-Eastman C, Fuentes L, Figueroa CR, Herrera R, Manriquez D, Latche A, Pech JC, Moya-Leon MA. VpAAT1, a gene encoding an alcohol acyltransferase, is involved in ester biosynthesis during ripening of mountain papaya fruit. J Agric Food Chem. 2010; 58: 5114-21.

31. Cumplido-Laso G, Medina-Puche L, Moyano E, Hoffmann T, Sinz Q, Ring L, Studart-Wittkowski C, Caballero JL, Schwab W, Munoz-Blanco J, Blanco-Portales R. The fruit ripening-related gene FaAAT2 encodes an acyl transferase involved in strawberry aroma biogenesis. J Exp Bot. 2012; 63: 4275-90.

32. Zhou DD, Sun Y, Li MY, Zhu T, Tu K. Postharvest hot air and UV-C treatments enhance aroma-related volatiles by simulating the lipoxygenase pathway in peaches during cold storage. Food Chem. 2019; 292: 294-303.

33. Domínguez T, Hernández ML, Pennycooke JC, Jiménez P, Martínez-Rivas JM, Sanz C, Stockinger EJ, Sánchez-Serrano JJ, Sanmartín M. Increasing $\omega-3$ desaturase expression in tomato results in altered aroma profile and enhanced resistance to cold stress. Plant Physiol. 2010; 153: 655-65. 
34. Wallis JG, Browse J. Mutants of Arabidopsis reveal many roles for membrane lipids. Prog Lipid Res. 2002; 41: 254-78.

35. Zhang YY, Yin XR, Xiao YW, Zhang ZY, Li SJ, Liu XF, Zhang B, Yang XF, Grierson D, Jiang GH, Klee HJ, Chen KS. An ETHYLENE RESPONSE FACTOR-MYB transcription complex regulates furaneol biosynthesis by activating QUINONE OXIDOREDUCTASE expression in strawberry. Plant Physiol. 2018; 178: 189-201.

36. Tanaka M, Takahata Y, Nakayama H, Nakatani M, Tahara M. Altered carbohydrate metabolism in the storage roots of sweetpotato plants overexpressing the SRF1 gene, which encodes a Dof zinc finger transcription factor. Planta. 2009; 230: 737-46.

37. Qi X, Li SX, Zhu YX, Zhao Q, Zhu DY, Yu JJ. ZmDof3, a maize endosperm-specific Dof protein gene, regulates starch accumulation and aleurone development in maize endosperm. Plant Mol Biol. 2017; 93: 7-20.

38. Feng BH, Han YC, Xiao YY, Kuang JF, Fan ZQ, Chen JY, Lu WJ. The banana fruit D of transcription factor MaDof23 acts as a repressor and interacts with MaERF9 in regulating ripening-related genes. J Exp Bot. 2016; 67: 2263-75.

39. Wu BP, Cao XM, Liu HR, Zhu CQ, Klee H, Zhang B, Chen KS. UDP-glucosyltransferase PpUGT85A2 controls volatile glycosylation in peach. J Exp Bot. 2019; 70: 925-36.

40. Yin XR, Chen KS, Allan AC, Wu RM, Zhang B, Lallu N, Ferguson IB. Ethylene-induced modulation of genes associated with the ethylene signaling pathway in ripening kiwifruit. J Exp Bot. 2008; 59: 2097-108.

41. Langfelder P, Horvath S. WGCNA: an R package for weighted correlation network analysis. BMC Bioinformatics. 2008; 9: 559.

42. Huang SX, Ding J, Deng DJ, Tang W, Sun HH, Liu DY, Zhang L, Niu XL, Zhang X, Meng M, Yu JD, Liu J, Han Y, Shi W, Zhang DF, Cao SQ, Wei ZJ, Cui YL, Xia YH, Zeng HP, Bao K, Lin L, Min Y, Zhang H, Miao M, Tang XF, Zhu YY, Sui Y, Li GW, Sun HJ, Yue JY, Sun JQ, Liu FF, Zhou LQ, Lei L, Zheng XQ, Liu M, Huang L, Song J, Xu CH, Li JW, Ye KY, Zhong SL, Lu BR, He GH, Xiao FM, Wang HL, Zheng HK, Fei ZJ, Liu YS. Draft genome of the kiwifruit Actinidia chinensis. Nat Commun. 2013; 4: 2640.

\section{Supplementary Information}

Additional file 1. Concentrations of volatile compounds detected in 'Hayward' kiwifruit during storage (ng/g FW).

Additional file 2 Fig. S1. An heatmap of volatile compounds detected in 'Hayward' kiwifruit in response to ethylene or 1-MCP treatment during storage. Fig. S2 PCA analysis of the volitial compounds and ethylene production in kiwifruit treated with control, ethylene $\left(100 \mu \mathrm{I} \mathrm{I}^{-1}, 24 \mathrm{~h}\right)$ and 1-MCP $\left(1 \mathrm{ll}^{-1}, 24 \mathrm{~h}\right)$. Fig. S3. Phylogenetic tree analysis of kiwifruit $A d A T 17$ and $A A T$ sequences in other species. Fig. S4. Phylogenetic tree of kiwifruit AdFAD1 with Arabidopsis thaliana AtFAD2-8, tomato SIFAD3/StFAD7 and PpFAD. Fig. S5. 
Phylogenetic tree of AdNAC5 with kiwifruit (A. chinensis and A. arguta) reported NACs and Arabidopsis thaliana NACs.

Additional file 3 Table S1. Aroma biosynthesis structural genes. Table S2. Primers for real-time PCR. Table S3. Sequences ( $5^{\prime}$ to $3^{\prime}$ ) for promoter isolation. Table S4. Primers for vector construction for dualluciferase assays.

\section{Figures}

A

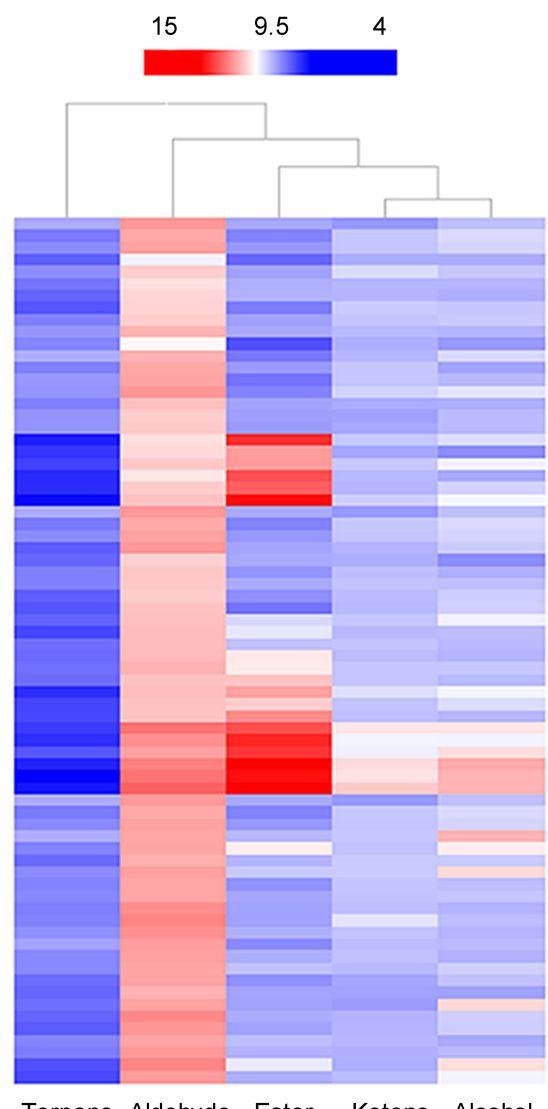

B
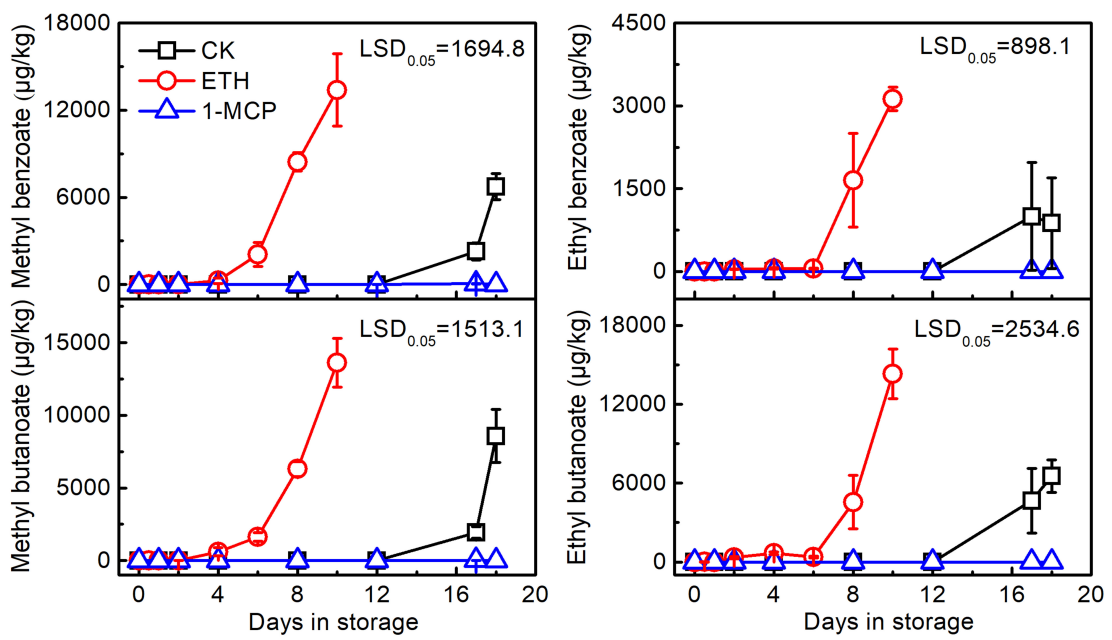

C

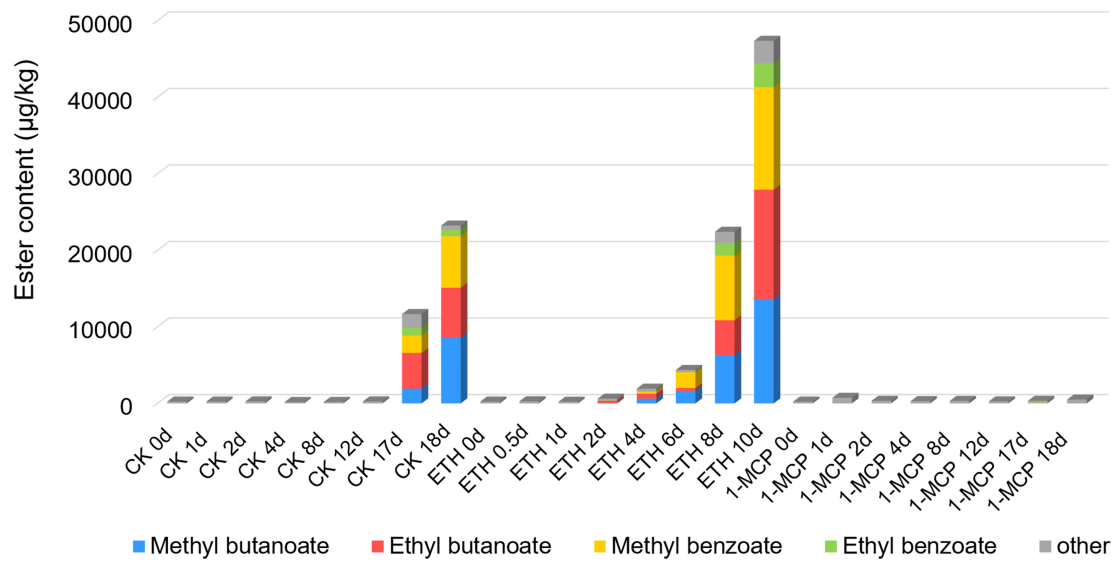

\section{Figure 1}

Analysis of volatile compounds in 'Hayward' kiwifruit. (A) Total alcohols, terpenes, aldehydes, ketones and esters of kiwifruit in response to ethylene or 1-MCP treatment during storage. Mature fruit were treated with $100 \mu \mathrm{L} \mathrm{L}-1$ ethylene (ETH), $1 \mu \mathrm{L} \mathrm{L}-1$ 1-MCP, or air (control, CK) for $24 \mathrm{~h}$ at $20^{\circ} \mathrm{C}$. (B) Profiles of methyl butanoate, methyl benzoate, ethyl butanoate, and ethyl benzoate in flesh tissues of ripening kiwifruit. Error bars indicate S.E.s from three replicates. LSD values represent least significant difference at $P=0.05$. (C) The proportion of methyl butanoate, methyl benzoate, ethyl butanoate, ethyl benzoate and other ester components in total esters. 
A
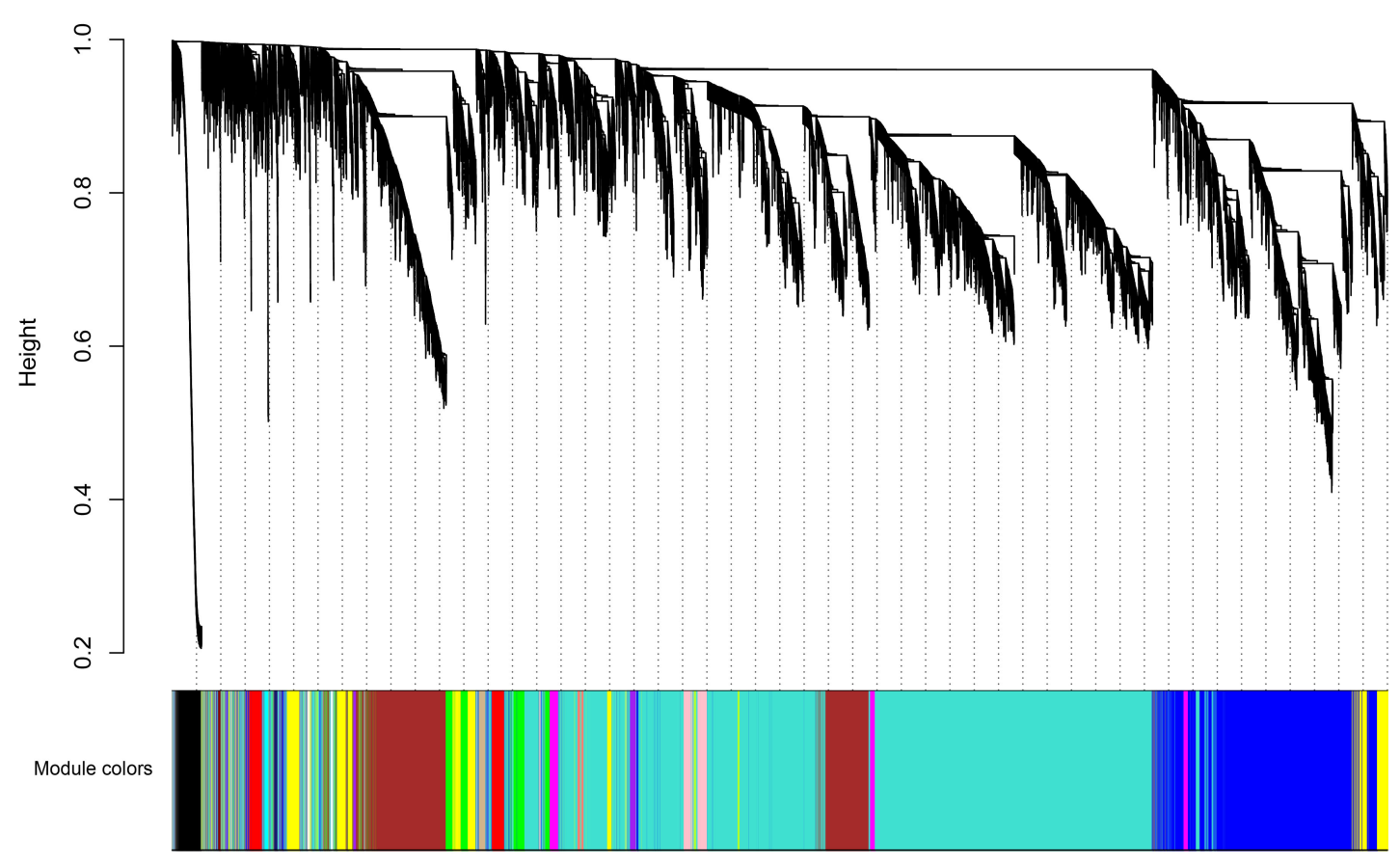

B

Module-trait relationships

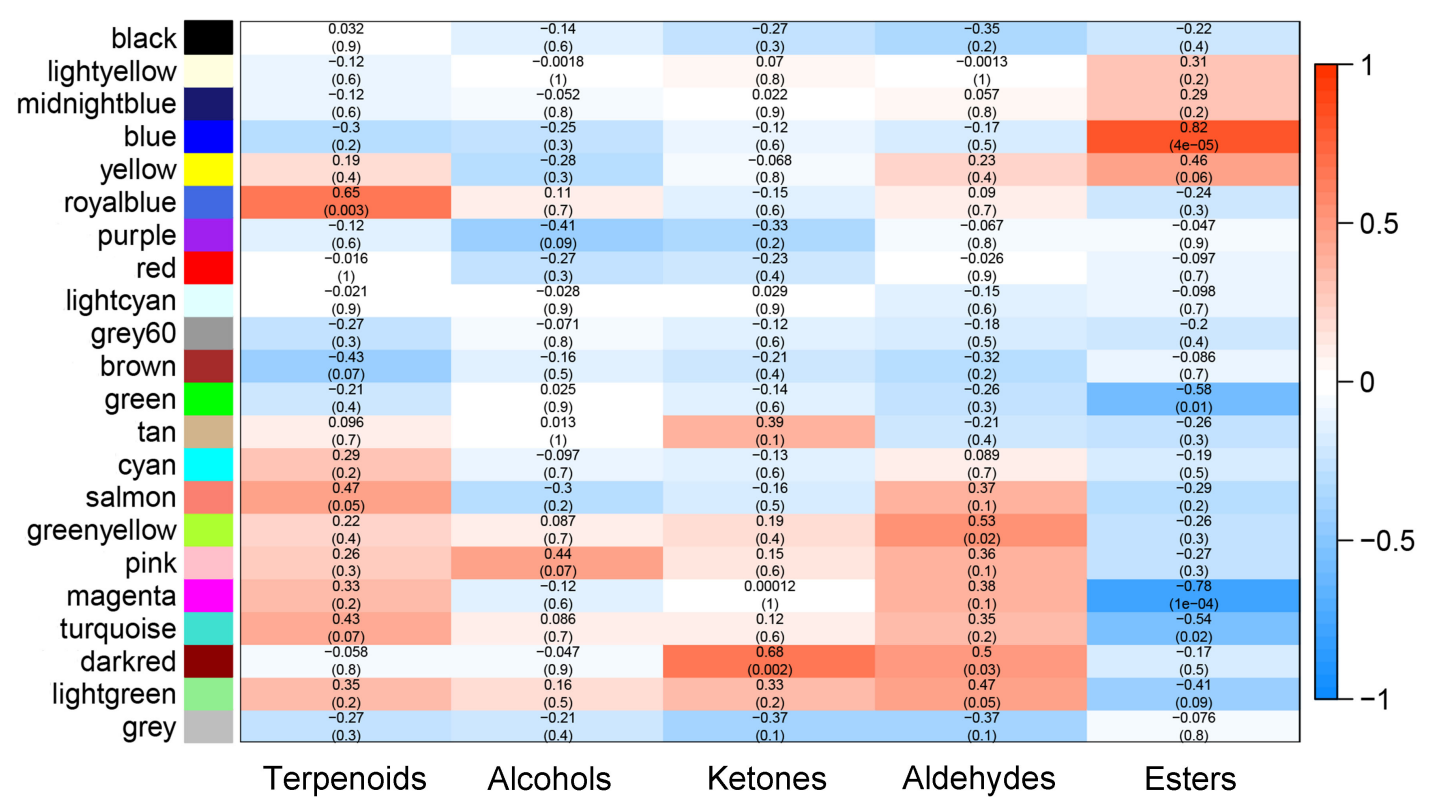

\section{Figure 2}

Co-expression network analysis of transcriptomes in relation to aroma contents during 'Hayward' kiwifruit fruit ripening. (A) Hierarchical cluster tree showing 22 modules of co-expressed genes. Each leaf represents one gene in the tree. (B) Module-flavor correlations and corresponding p-values. Each row corresponds to a cluster. Each column corresponds to a volatile compound. The left panel shows 22 modules and the right panel is a color scale for module trait correlation from -1 to 1 . 


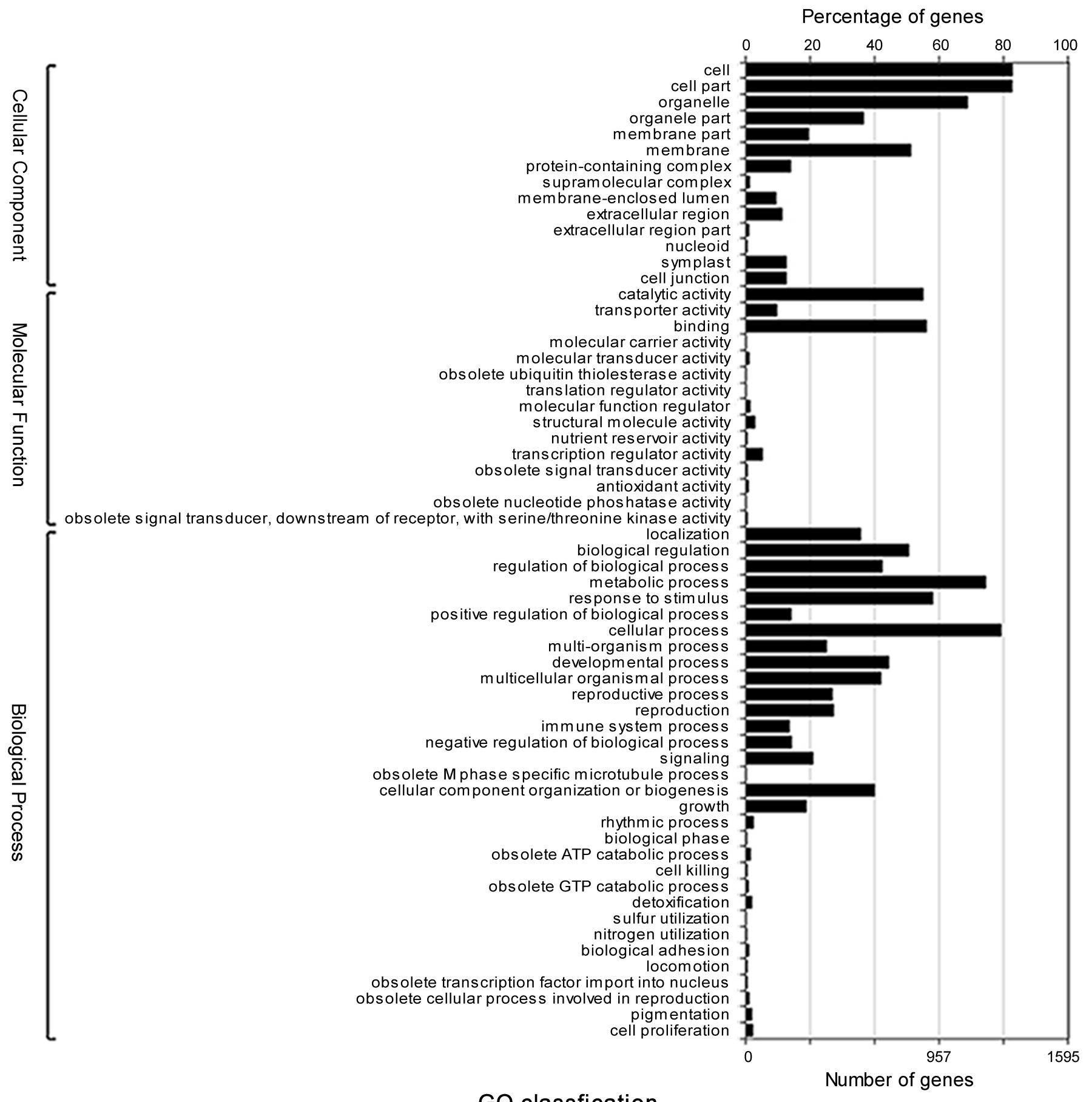

Figure 3

GO annotation of co-expressed genes. 
A

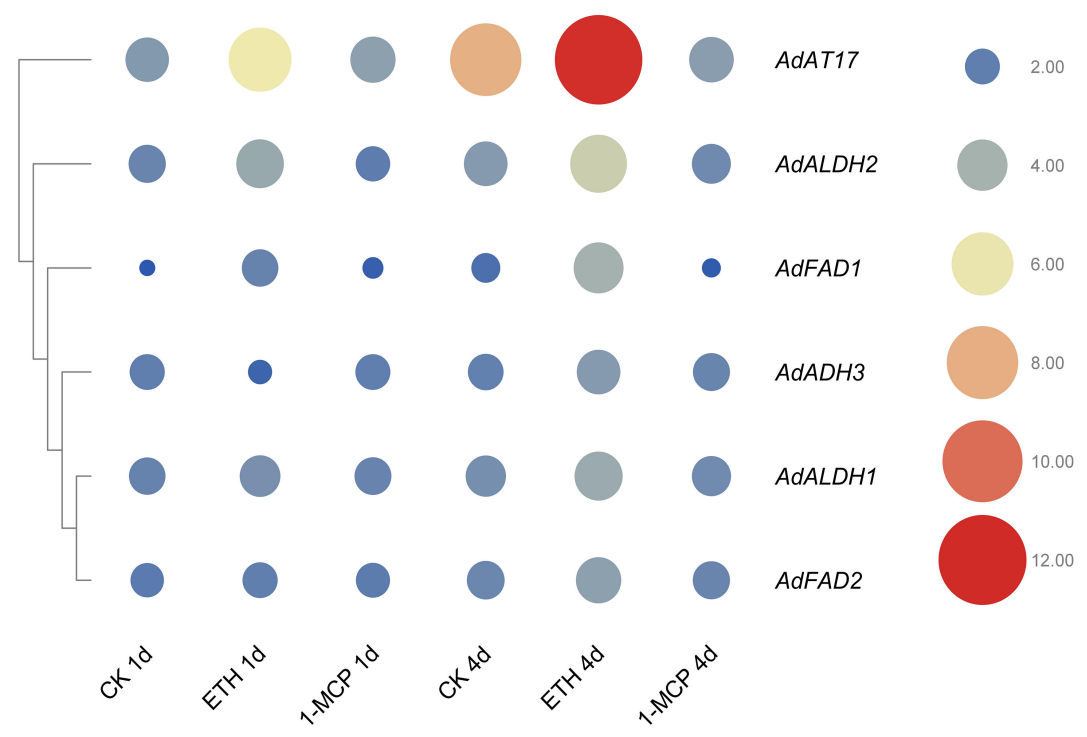

B
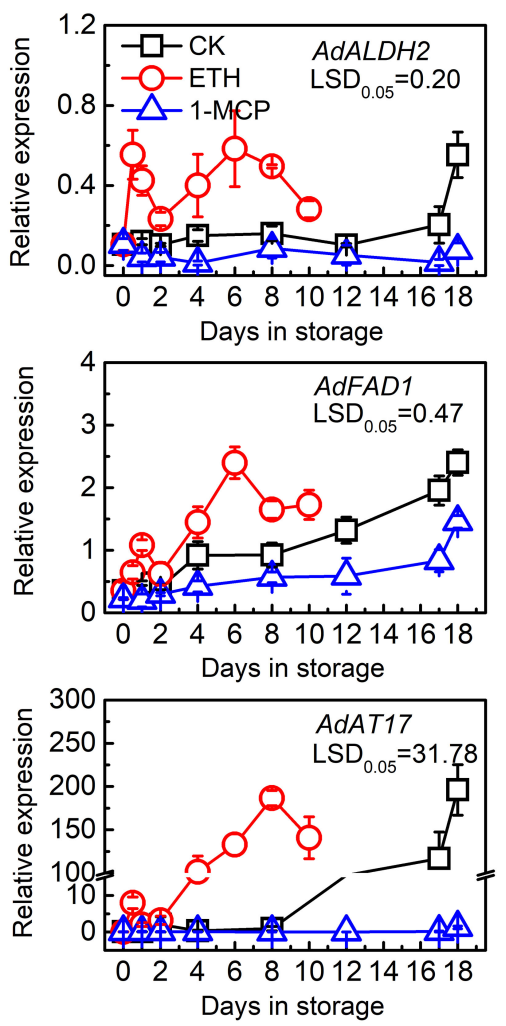

\section{Figure 4}

Expression of structural genes in response to ethylene or 1-MCP treatment during 'Hayward' kiwifruit storage. Mature fruit were treated with $100 \mu \mathrm{L}$ L-1 ethylene (ETH), $1 \mu \mathrm{L} \mathrm{L-1}$ 1-MCP, or air (control, CK) for $24 \mathrm{~h}$ at $20^{\circ} \mathrm{C}$. (A) Structural genes with putative function in kiwifruit ester biosynthesis from RNA-seq. Transcript abundance is indicated by color and size, the bigger and redder the circle, the higher is the expression. Mean data was obtained from three replicates. (B) Gene expression was analyzed by realtime PCR. Error bars represent S.E.s from three replications. LSD values represent least significant difference at $P=0.05$. 


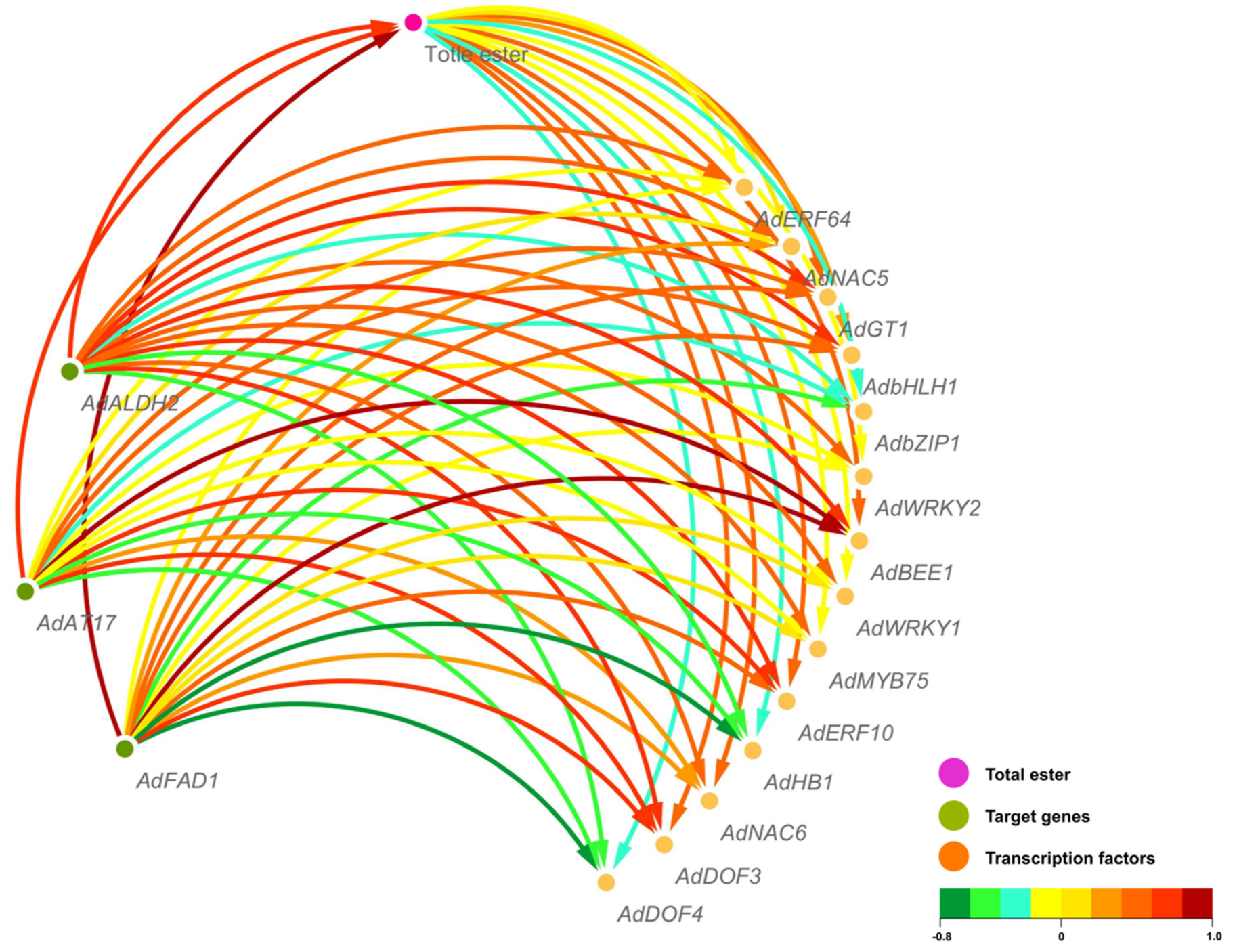

Figure 5

Correlation network analysis for structural genes, transcription factors and esters content. The colors of arrows represent the correlations, as indicated by colored bar. 

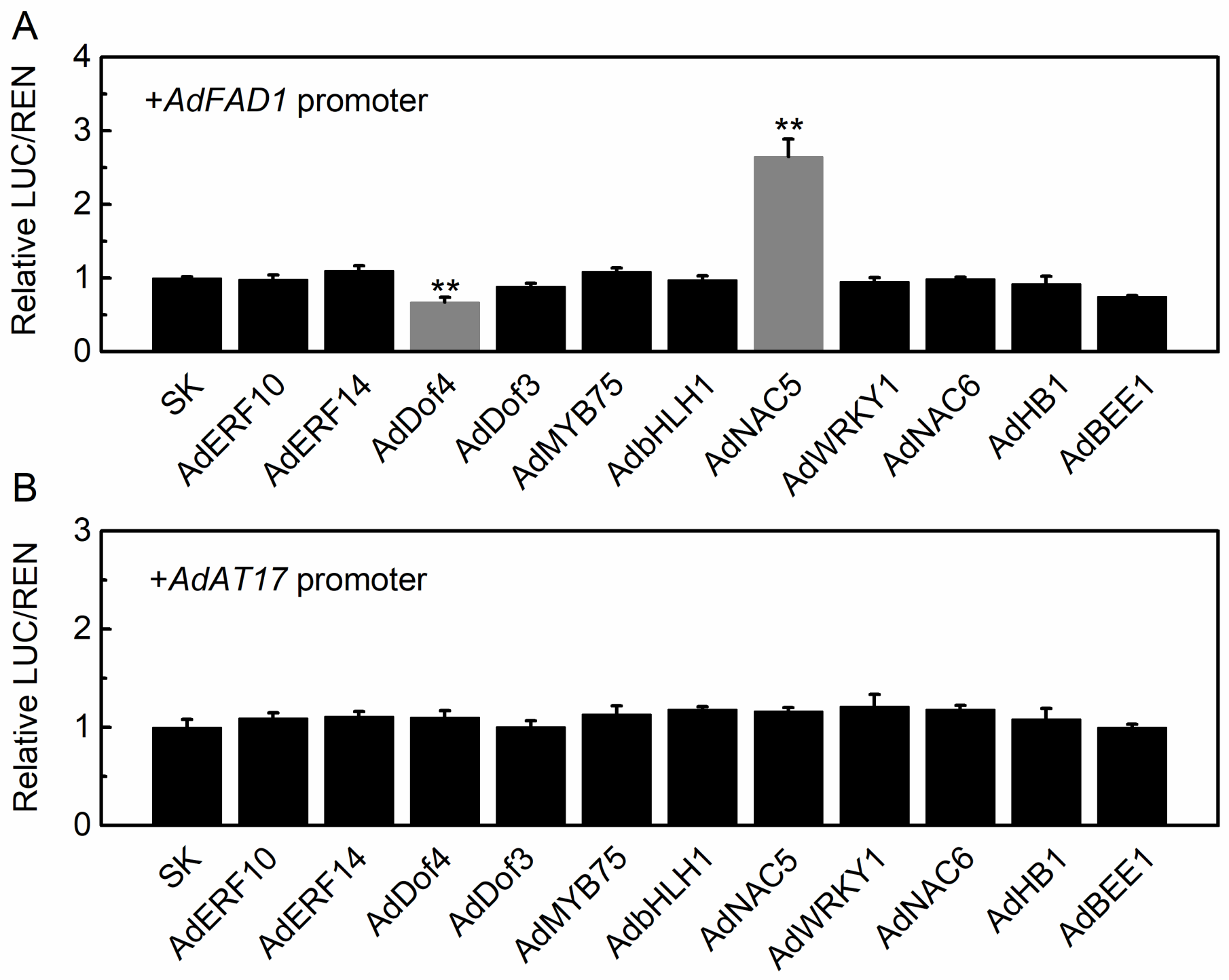

Figure 6

Regulatory effects of transcription factors on promoters of AdFAD1 (A) and AdAT17 (B), by dualluciferase assays. The ratio of LUC/REN of the empty vector plus promoter was set as 1 . SK refers to the empty pGreen II 002962 -SK vector. Error bars indicate S.E.s from three replicates $\left({ }^{\star} P<0.05,{ }^{\star}{ }^{*} P<0.01\right.$ and $\star \star \star P<0.001)$.

\section{Supplementary Files}

This is a list of supplementary files associated with this preprint. Click to download.

- Additionalfile2figurerevision.docx

- Additionalfile1aromacompounds.xlsx

- Additionalfile3tablerevision.docx 